\title{
Improvements in the Stability of Frozen Minced Meat from Gadoid Species Obtained
}

\section{by a Mixing Treatment}

\author{
Toru Mizuguchi ${ }^{*}$, Keiko Kumazawa and Shinya Yamashita \\ Central Research Laboratory, Nippon Suisan Kaisha Ltd., Hachioji, Tokyo 192-0991, Japan
}

Received June 29, 2012; Accepted December 27, 2012

The suppression of trimethylamine- $N$-oxide decomposition to dimethylamine (DMA) and formaldehyde is required to ensure the stability of frozen minced meat from gadoid species. The effects of a mixing treatment on the stability of frozen minced meat were investigated. Minced meat samples from pollock, southern blue whiting (SBW), and hoki were mixed for $1-10$ min with $8.3 \%$ sucrose using a silent cutter and stored at $-23^{\circ} \mathrm{C}$ for 6 months. The salt solubility of minced pollock and SBW, but not hoki meat, was stabilized by the 10-min mixing treatment, and DMA formation was reduced with increased mixing time, which may have been due to oxidation of the minced meat by the $\mathrm{O}_{2}$ in the air. Minced SBW meat mixed for 10 min had similar properties to surimi even though water- and oil-holding capacities were slightly different.

Keywords: dimethylamine, formaldehyde, gadoid species, minced meat, mixing, oxidation, salt solubility, trimethylamine- $N$ oxide

\section{Introduction}

The ordinary muscle of gadoid species, such as Alaskan pollock, southern blue whiting, and hoki, contains 60 - $80 \mathrm{mM}$ trimethylamine- $N$-oxide (TMAO) (Mizuguchi et al., 2011a), which decomposes to equimolar amounts of dimethylamine (DMA) and formaldehyde more rapidly during freezing when compared with other species (Tokunaga, 1970). DMA has a fishy smell, and formaldehyde is a strong protein denaturant. Therefore, TMAO decomposition is a reason why proteins in gadoid species have poor stability when frozen (Castell et al., 1973; Reppond et al., 1985; Rehbein and Orlick, 1990). Thus, the suppression of TMAO decomposition is essential for increasing the stability of frozen gadoid meat. Boer and Fennema reported that the treatment of minced Alaskan pollock meat by mixing before freezing suppresses TMAO decomposition and results in less toughening of the meat during storage at $-10^{\circ} \mathrm{C}$ (Boer and Fennema, 1989). Several researchers have shown that oxygen suppresses TMAO decomposition during freezing (Reece, 1983; Kimura et al., 2006; Sato et al., 2011). Racicot et al. (1984) demonstrated that oxidizing agents, such as $\mathrm{H}_{2} \mathrm{O}_{2}$, reduce the TMAO decomposition rate during freezing.

*To whom correspondence should be addressed. E-mail: tooru_mizuguchi@nissui.co.jp
However, these reports did not evaluate the effects of TMAO decomposition suppression on protein properties. The mixing treatment results in protein denaturation because of the applied mechanical force and increased temperature. Kawasaki et al. $(1991,1992)$ reported that the triglyceride oxidation products in fish meat lead to deterioration in myofibrillar $\mathrm{Ca}$ ATPase activity and cross-linking of the myosin heavy chain (MHC). Thus, oxidizing agents may cause fish proteins to lose certain beneficial properties, such as their gel-formation ability, water-holding capacity and emulsifiability. These undesirable effects offset the benefits of suppressing TMAO decomposition during freezing.

The purpose of this study was to investigate the effects of a mixing treatment on the stability of protein properties when minced meats from gadoid species were frozen at a sub-zero temperature and to determine whether minced meats could be used as a novel alternative to surimi or raw materials in a wide range of fish products, such as fish cakes. If TMAO decomposition could be suppressed while maintaining the desirable protein properties in these meats, the quality of seafood products could be improved and marine resources could be used more efficiently.

\section{Materials and Methods}

Fish samples Alaskan pollock (Theragra chalcogram- 
$m a$ ) was caught by trawling in the Bering Sea, and southern blue whiting (SBW) (Micromesistius australis) and hoki (Macruronus magellanicus) were caught by trawling off the coast of Argentina. All fish samples were stored immediately in ice until use.

Mixing procedure Minced meats from the three species were prepared from skinless fillets using a meat separator (605; BAADER, Lübeck, Germany) with a 3-mm-diameter mesh. Sucrose was added to the minced meat at a final concentration of $8.3 \%(\mathrm{w} / \mathrm{w})$. The meat was gently mixed with a scraper in a mixing bowl of a silent cutter (SCP-2A; Hanaki, Tokyo, Japan), before the meats were mixed using the silent cutter for $1-10 \mathrm{~min}$. The silent cutter had three blades that rotated at $1450 \mathrm{rpm}$ and a $12-\mathrm{L}$ bowl that rotated at $10 \mathrm{rpm}$. The samples were packed into polyethylene bags and frozen in a contact freezer until the temperature reached $-25^{\circ} \mathrm{C}$, and kept at $-23^{\circ} \mathrm{C}$ for 6 months.

Salt solubility The frozen samples were cut into small pieces and homogenized in ice for $90 \mathrm{~s}$ with 10 volumes of $20 \mathrm{mM}$ Tris- $\mathrm{HCl}$ buffer $(\mathrm{pH} 7.5)$ containing $0.1 \mathrm{M} \mathrm{KCl}$ and $1 \%$ trisodium citrate. The homogenates were centrifuged at $2800 \times \mathrm{g}$ for $10 \mathrm{~min}$ at $4^{\circ} \mathrm{C}$. This procedure was performed twice. The precipitates were homogenized gently with 10 volumes of $20 \mathrm{mM}$ Tris- $\mathrm{HCl}$ buffer $(\mathrm{pH} 7.5)$ containing 0.5 $\mathrm{M} \mathrm{KCl}$. Adenosine triphosphate was added at a final concentration of $1 \mathrm{mM}$ and the resulting solutions were stored at $4^{\circ} \mathrm{C}$ for $18 \mathrm{~h}$. The homogenates were then centrifuged at $5500 \times g$ at $4{ }^{\circ} \mathrm{C}$ for $20 \mathrm{~min}$. The protein content of the supernatant and total protein were determined using the Biuret method with bovine serum albumin as the standard (Gornall et al., 1949). The results were expressed as the percentage supernatant protein in the total protein.

DMA determination The amount of DMA produced was used to evaluate formaldehyde production. The copper dithiocarbamate procedure was used to measure DMA (Dyer and Mounsey, 1945). The frozen samples (5 g) were cut into small pieces and extracted using $45 \mathrm{~mL}$ of trichloroacetic acid (TCA) solution at a concentration of $5 \%(\mathrm{w} / \mathrm{w})$, before diluting the extract with water to obtain a TCA concentration of $1.25 \%$. Copper-ammonia solution $(0.4 \mathrm{~mL})$ and a benzene solution containing $5 \%$ carbon disulfide $(4 \mathrm{~mL})$ were added to 4-mL aliquots of extracts before the mixtures were incubated at $40^{\circ} \mathrm{C}$ for $5 \mathrm{~min}$ and then shaken vigorously. The color intensity of the benzene layer was measured spectrophotometrically at $440 \mathrm{~nm}$. All chemicals were purchased from Wako Pure Chemical Industries (Osaka, Japan).

Effects on DMA formation after mixing in $\mathrm{N}_{2}, \mathrm{O}_{2}$, and $\mathrm{CO}_{2}$ atmospheres Minced SBW meat was prepared as described above. Before mixing, $8.3 \%$ sucrose $(\mathrm{w} / \mathrm{w})$ was added to the minced meat, which was gently mixed with a scraper in the mixing bowl of the silent cutter. The bowl was covered with a lid and each test gas $\left(\mathrm{N}_{2}, \mathrm{O}_{2}\right.$, or $\left.\mathrm{CO}_{2}\right)$ was released into the mixing bowl from a nozzle on the cover for $60 \mathrm{~s}$ at $20 \mathrm{nl} / \mathrm{min}$. The gas was supplied constantly to the minced meat at $20 \mathrm{nl} /$ min during mixing for $10 \mathrm{~min}$. Samples were then packed into polyethylene bags of 0.04-mm thickness (Unipack H-4; Seisannipponsha Ltd., Tokyo, Japan), before sealing the bags with a little air, and blast frozen at $-40^{\circ} \mathrm{C}$ for $20 \mathrm{~h}$. In this test, samples were stored at $-10^{\circ} \mathrm{C}$ for 2 weeks to accelerate DMA formation because freezing increased the concentration of solutes, which enhanced TMAO degradation into DMA and formaldehyde (Mizuguchi et al., 2011b).

Proximate component analysis The moisture content of each fish meat was determined after drying the samples at $115^{\circ} \mathrm{C}$ for $3 \mathrm{~h}$. The protein content was measured using the semi-micro Kjeldahl method (nitrogen coefficient was 6.25). The crude fat content was determined gravimetrically using acid hydrolysis and diethyl ether extraction (William, 2005). The ash content was measured after ignition to a constant weight at $550^{\circ} \mathrm{C}$. Carbohydrate was estimated by subtracting the moisture, protein, fat, and ash contents from the total weight. Next, $3 \mathrm{~g}$ of the sample was homogenized with 27 $\mathrm{ml}$ of water, and the homogenate was centrifuged at 2800 $\times g$ at room temperature. The salt content was measured as the conductivity of the homogenate using a digital salt meter (NS-3P; Merbabu Trading Co., Ltd, Osaka, Japan). The pH was measured using a $\mathrm{pH}$ meter with a glass electrode (F-23; Horiba, Kyoto, Japan).

Protein solubility in solutions with varying ionic strength Minced SBW meat was prepared by mixing for $10 \mathrm{~min}$, as described in the mixing procedure above, and was used after freezing at $-23^{\circ} \mathrm{C}$ for 6 months. SBW surimi (A grade) containing $3.7 \%$ sorbitol, $3.7 \%$ sucrose, and $0.28 \%$ polyphosphates was used after storage at $-23^{\circ} \mathrm{C}$ for 5 months. The frozen minced meat and surimi samples were cut into small pieces and homogenized on ice for $90 \mathrm{~s}$ with 10 volumes of $20 \mathrm{mM}$ Tris- $\mathrm{HCl}$ buffer $(\mathrm{pH} 7.5)$ containing $1 \%$ trisodium citrate and $0.1-0.5 \mathrm{M} \mathrm{KCl}$.

The homogenates were centrifuged at $5500 \times g$ at $4^{\circ} \mathrm{C}$ for $20 \mathrm{~min}$. The protein content of the supernatant and the total protein were determined by the Biuret method with bovine serum albumin as the standard (Gornall et al., 1949). The results were expressed as the percentage supernatant protein in the total protein.

Water-holding capacity Minced SBW meat was prepared by mixing for $10 \mathrm{~min}$, as described in the mixing procedure above, and used after frozen storage at $-23^{\circ} \mathrm{C}$ for 6 months. Minced meat was partially thawed at room temperature within $30 \mathrm{~min}$ and ground using a silent cutter until the temperature reached $8^{\circ} \mathrm{C}$. The paste was inserted into a poly- 
vinylidene chloride tube (30-mm diameter, 20-cm length), boiled at $90^{\circ} \mathrm{C}$ for $30 \mathrm{~min}$, and cooled with running water. After the temperature of the sample was adjusted to $20^{\circ} \mathrm{C} \pm$ $2^{\circ} \mathrm{C}$, each sample was cut into $3 \mathrm{~mm} \times 3 \mathrm{~mm}$-pieces, and 3 $\mathrm{g}$ of sample was weighed into a preweighed centrifuge tube that contained three layers of filter paper (Toyo No. 3) in the bottom to absorb any drips. Each sample was centrifuged at $700 \times g$ for $10 \mathrm{~min}$ at $10^{\circ} \mathrm{C}$. The sample was completely removed from the tube and the tube was weighed with the filter papers. The centrifugal drip loss was calculated using the following equation and was referred to as the water-holding capacity (WHC).

$$
\mathrm{WHC}(\%)=\mathrm{W} 2-\mathrm{W} 1 / \mathrm{W} 0 \times 100
$$

where $\mathrm{W} 0$ is the weight of the sample (g), W1 is the weight of the centrifuge tube with the filter papers, and W2 is the weight after centrifugation of the tube with the sample and filter papers after removing the sample (g).

Oil-holding capacity Minced meat prepared as described above was ground in a silent cutter with $10 \%(\mathrm{w} / \mathrm{w})$ soybean oil until the temperature reached $8^{\circ} \mathrm{C}$. The paste was inserted into a polyvinylidene chloride tube $(30-\mathrm{mm}$ diameter, 20-cm length), boiled at $90^{\circ} \mathrm{C}$ for $30 \mathrm{~min}$, and cooled
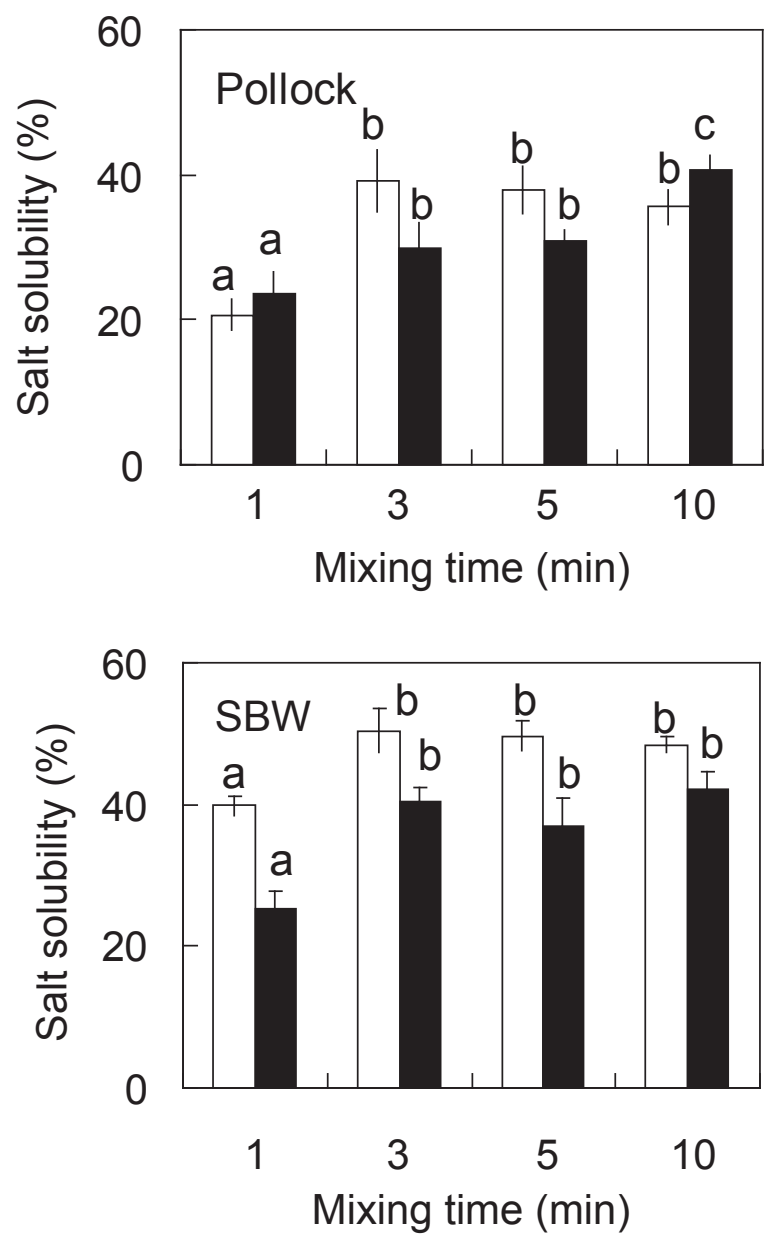

with running water. After the temperature of the sample was adjusted to $20^{\circ} \mathrm{C} \pm 2{ }^{\circ} \mathrm{C}$, the drip loss was calculated using the following equation and was referred to as the oil-holding capacity (OHC).

$$
\mathrm{OHC}(\%)=\mathrm{W} 1 / \mathrm{W} 0 \times 100
$$

where $\mathrm{W} 0$ is the weight of the sample $(\mathrm{g})$ and $\mathrm{W} 1$ is the weight of the drip (g).

Statistical analysis One-way analysis of variance (ANOVA) was performed, followed by Duncan's multiple range tests to detect any differences among the means. Statistical analysis was performed using SPSS version 10.1 for Windows (SPSS Inc., Chicago, IL, USA), with the significance level set at $P<0.05$.

\section{Results}

Effects of mixing on the protein properties The minced meats were mixed with $8.3 \%$ sucrose using a silent cutter for $1-10 \mathrm{~min}$. After mixing treatment for $10 \mathrm{~min}$, the temperature of the minced meat reached approximately $12^{\circ} \mathrm{C}$. The salt solubility of meat from each species after mixing for 1 min was lower than $3-10$ min immediately after freezing (Fig. 1). After 6 months, the salt solubility increased with

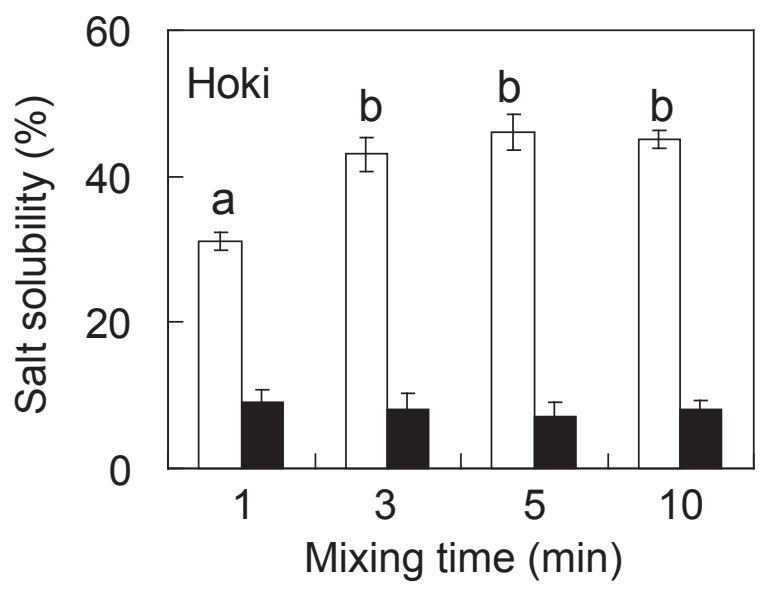

Fig. 1. Effects of the mixing treatment on the salt solubility of minced meats from the three gadoid species after frozen storage at $-23^{\circ} \mathrm{C}$ for 6 months. Sucrose $(8.3 \% \mathrm{w} / \mathrm{w})$ was added to the minced meats. Results are presented as mean \pm SD for triplicate measurements. Open bars, immediately after freezing (less than 3 days); filled bars, after storage at $-23^{\circ} \mathrm{C}$ for 6 months. Significant differences after the same storage period are indicated by different letters. 
a longer mixing time in pollock. The salt solubilities of the minced SBW meats were almost the same as the minced meats mixed for $3-10 \mathrm{~min}$, whereas the decrease in ratio of minced SBW meat mixed for 10 min was the lowest among the meats mixed for $1-5 \mathrm{~min}$; the decrease in the ratios of the meats mixed for $1,3,5$, and $10 \mathrm{~min}$ were $36 \%, 19 \%$, $25 \%$, and $13 \%$, respectively. The salt solubility of hoki was $<$ $10 \%$ regardless of the mixing time, and the hoki protein was denatured significantly.

Effects of mixing on DMA formation Minced meats were mixed with $8.3 \%$ sucrose using a silent cutter for $1-10$ min. The mixing time had no effect on DMA formation immediately after freezing. After 6 months of storage at $-23^{\circ} \mathrm{C}$, DMA formation was suppressed with increased mixing time (Fig. 2). Specifically, mixing for 3, 5, and 10 min reduced DMA formation by $17 \%, 23 \%$, and $37 \%$, respectively, in pollock compared with mixing for $1 \mathrm{~min}$; SBW showed a similar tendency to pollock. Therefore, it is considered that the mixing treatment inhibited DMA formation and the protein properties were preserved for at least 6 months because the salt solubility increased inversely to DMA formation in pollock and SBW. DMA formation declined by $28 \%$ in minced hoki meat mixed for 10 min compared with minced
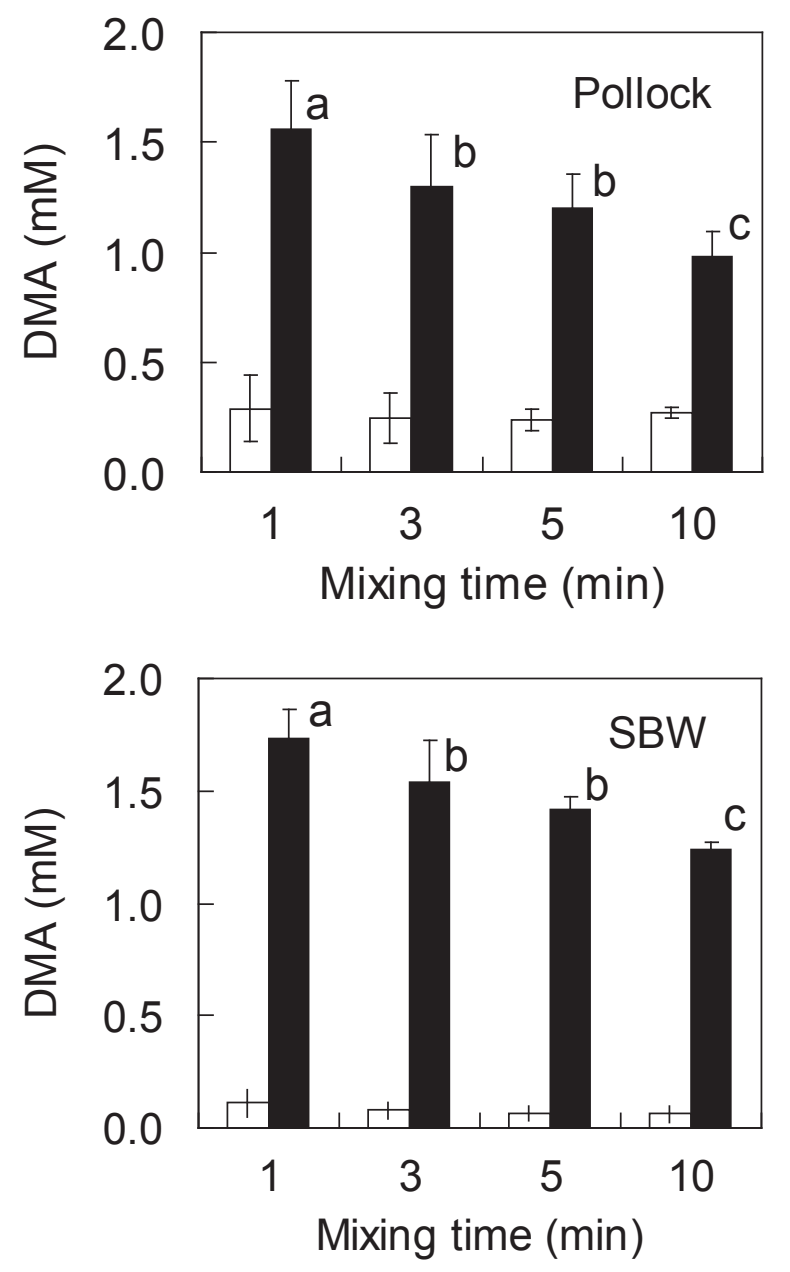

hoki meat mixed for $1 \mathrm{~min}$; however, DMA was significantly formed during freezing (approx. $9 \mathrm{mM}$ ).

Effects on DMA formation after mixing in $\mathrm{N}_{2}, \mathrm{O}_{2}$, and $\mathrm{CO}_{2}$ atmospheres The mixing of minced pollock, SBW, and hoki meats inhibited DMA formation during freezing. To confirm that our findings were because of the action of oxygen, minced SBW meat was mixed in the air and three different gases $\left(\mathrm{N}_{2}, \mathrm{O}_{2}\right.$, or $\left.\mathrm{CO}_{2}\right)$, before testing DMA formation at a sub-zero temperature. The $\mathrm{pH}$ of the minced meat was not affected by the mixing treatment in any of the atmospheres (data not shown). After storage at $-10^{\circ} \mathrm{C}$ for 2 weeks, the DMA concentration in minced meat mixed in the air was $1.9 \mathrm{mM}$ (Fig. 3). DMA formation was accelerated in minced meat mixed in $\mathrm{N}_{2}(2.3 \mathrm{mM})$. DMA formation was suppressed when the minced meat was mixed in $\mathrm{O}_{2}$ or $\mathrm{CO}_{2}$ compared with that in air and $\mathrm{N}_{2}$. No DMA was formed when the minced meat was mixed for $10 \mathrm{~min}$ in the presence of $\mathrm{O}_{2}$ and stored at $-10^{\circ} \mathrm{C}$ for 2 weeks.

Proximate component analysis of minced meat and surimi from $S B W$ The moisture content of the minced meat was $1.3 \%$ lower than that of surimi, and the protein, carbohydrate, fat and ash contents of minced meat were higher than those of surimi (Table 1). The salt concentration and

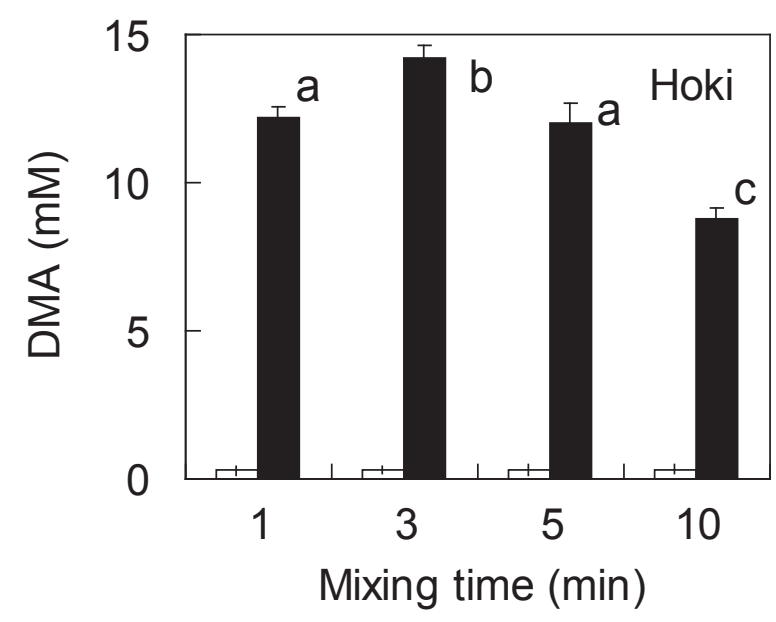

Fig. 2. Effects of the mixing treatment on DMA formation in minced meats from the three gadoid species after frozen storage at $-23^{\circ} \mathrm{C}$ for 6 months. Sucrose $(8.3 \% \mathrm{w} / \mathrm{w})$ was added to the minced meats. Results are presented as mean \pm SD for triplicate measurements. Open bars, immediately after freezing (less than 3 days); filled bars, after storage at $-23^{\circ} \mathrm{C}$ for 6 months. Significant differences after the same storage period are indicated by different letters. 


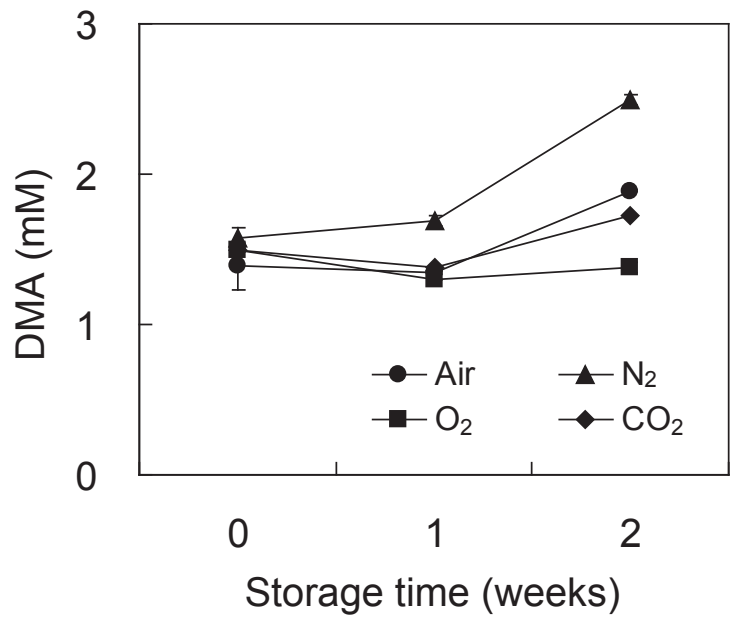

Fig. 3. Effects of different gases on DMA formation in minced SBW meat. Results are presented as mean \pm SD for triplicate measurements.

Table 1. Comparison of minced meat and surimi components from SBW.

\begin{tabular}{lcc}
\hline & Minced meat & Surimi \\
\hline Moisture (\%) & $73.6 \pm 0.2$ & $74.9 \pm 0.1$ \\
Protein (\%) & $16.5 \pm 0.8$ & $16.2 \pm 0.6$ \\
Fat (\%) & $0.4 \pm 0.2$ & $0.2 \pm 0.1$ \\
Ash (\%) & $1.0 \pm 0.1$ & $0.6 \pm 0.1$ \\
Carbohydrate (\%) & 8.5 & 8.1 \\
\hline Salt (\%) & $0.6 \pm 0.04$ & $0.3 \pm 0.06$ \\
pH & $7.1 \pm 0.1$ & $7.2 \pm 0.1$ \\
\hline
\end{tabular}

Values represent mean \pm standard deviation of triplicate measurements.

$\mathrm{pH}$ of the minced meat were almost the same as those of the raw material, i.e., a higher salt concentration in the minced meat with no leaching process. The higher $\mathrm{pH}$ in surimi was because of polyphosphates. The differences between minced meat and surimi prepared from SBW were because of differences in the preparation methods and ingredients.

Protein solubility in solutions with varying ionic strength The solubilities of the mixed minced meat and surimi samples from SBW in $20 \mathrm{mM}$ Tris-HCl buffer containing $0.1 \mathrm{M}$ $\mathrm{KCl}$ were $12.9 \%$ and $4.5 \%$, respectively (Fig. 4), because the surimi manufacturing process involves two leaching steps to remove water-soluble protein. The mixed minced meat and surimi samples had similar curves with increasing $\mathrm{KCl}$ concentrations of $0.1-0.5 \mathrm{M}$. At $0.5 \mathrm{M} \mathrm{KCl}$, the highest solubility of the mixed minced meat was $70 \%$ and that of the surimi sample was $58 \%$.

Water- and oil-holding capacity The water- and oilholding capacities of fish meat are important properties because they affect the quality and yield of the final products.

The centrifugal drip loss was measured to evaluate WHC

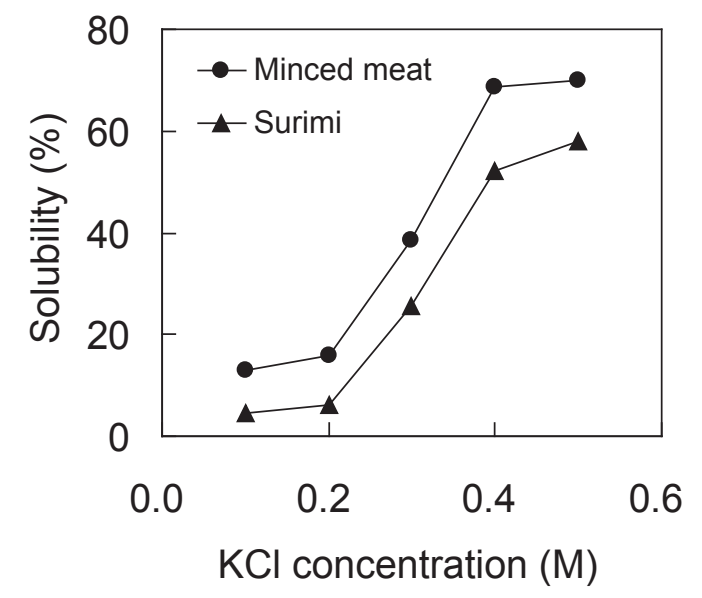

Fig. 4. Effects of ionic strength $(\mathrm{KCl})$ on solubility of minced meat and surimi from SBW.

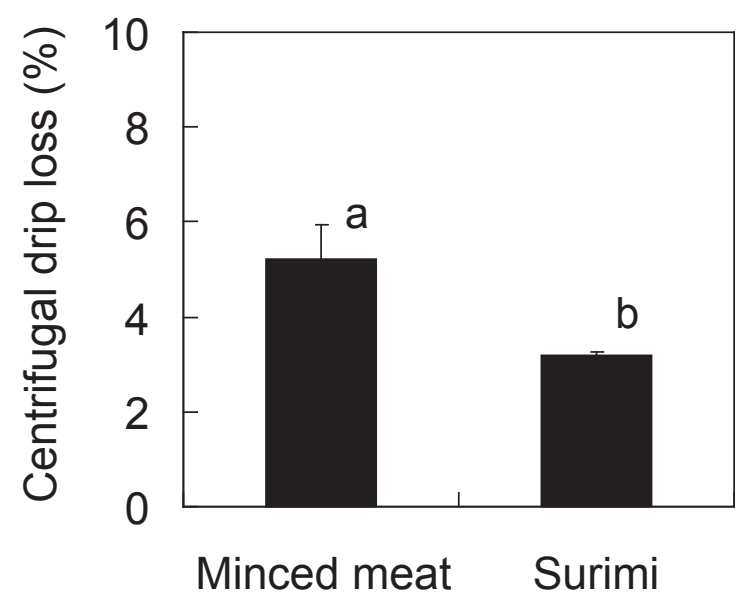

Fig. 5. Comparison of the water-holding capacity of minced SBW meat and SBW surimi after boiling. Results are presented as mean \pm SD for triplicate measurements. Significant differences are indicated by different letters.

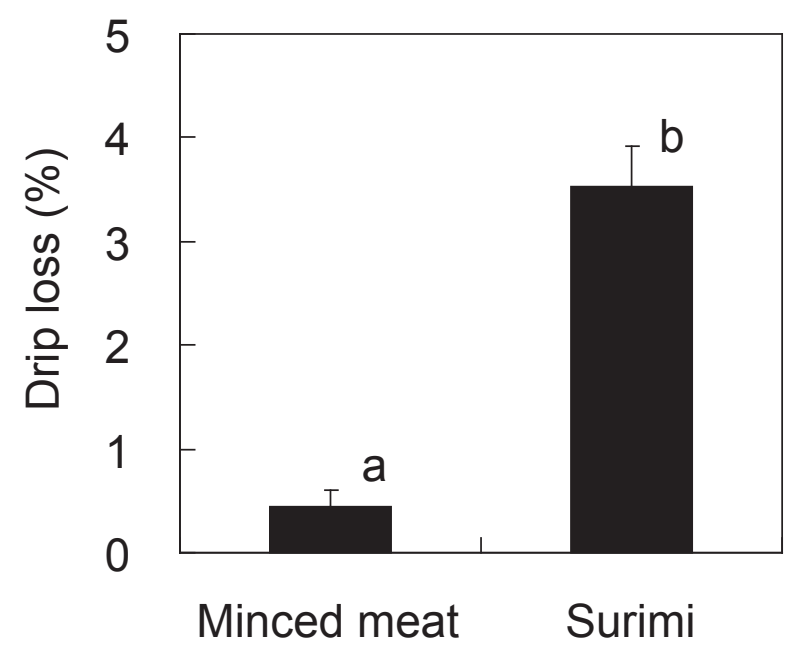

Fig. 6. Comparison of the oil-holding capacity of minced SBW meat and SBW surimi after boiling. Results are presented as mean \pm SD for triplicate measurements. Significant differences are indicated by different letters. 
of the meat samples after storage for 6 months. The centrifugal drip loss of the minced SBW meat was $2 \%$ higher than that of surimi (Fig. 5). Conversely, when soybean oil was added to the meats, the drip loss of the minced meat was $3 \%$ lower than that of the surimi (Fig. 6). The WHC and OHC capacities are influenced by $\mathrm{pH}$, protein concentration, gelforming ability, etc. We did not face any major issue with the capacities of the minced meat, which suggests that the minced meat can be used as raw materials in a wide range of fish products, such as fish cake and fish fry.

\section{Discussion}

Previous studies demonstrated that mixing treatment reduces DMA formation in frozen fish meat (Boer and Fennema, 1989). However, the effects of mixing on protein properties during freezing have not yet been revealed. It is also known that mixing treatments lead to protein denaturation. We revealed the effects of a mixing treatment on the protein properties of three gadoid species. For all three species, the minced meats mixed with sucrose for 1 min showed lower salt solubility immediately after freezing than when mixed for 3-10 min. Mixing for $1 \mathrm{~min}$ may be insufficient for achieving a uniform sucrose distribution and for dissolving the sucrose in the minced meats. After 6 months, the salt solubility of minced pollock meat mixed for 10 min was higher than that of the minced meats mixed for $1-5 \mathrm{~min}$. Gel forming ability was also examined in this study, and the results showed a similar tendency to that of salt solubility (data not shown).

DMA has a fishy smell and formaldehyde, which is produced in equimolar amounts to DMA from TMAO, has a great influence on protein properties. It is difficult to measure formaldehyde accurately (Kleeberg and Klinger, 1982); thus, the amount of DMA was measured to evaluate the formaldehyde production in this study. DMA formation was suppressed with increased mixing time, which was similar to a previous report (Boer and Fennema, 1989). Thus, it is considered that minced meats mixed for $10 \mathrm{~min}$ had a higher salt solubility because of differences in the formaldehyde production levels during freezing. The DMA concentration was approximately $1 \mathrm{mM}$ in pollock and SBW after mixing for $10 \mathrm{~min}$ followed by freezing at $-23^{\circ} \mathrm{C}$ for 6 months. Previous studies have reported that millimolar levels of formaldehyde affect the properties of fish proteins (Tokunaga, 1974; Sotelo et al., 1995; Tokunaga, 1964; Careche and Li-chan, 1997). Although $1 \mathrm{mM}$ DMA in fish meat is unlikely to be a sufficiently low level, the mixing treatment may contribute to maintaining protein stability during freezing. The DMA concentration was approximately $9 \mathrm{mM}$, and protein denaturation was observed in hoki, even when the minced meat was mixed for $10 \mathrm{~min}$. Hoki generates DMA rapidly compared with other gadoid species, such as pollock and SBW (Mizuguchi et al., 2011a). Although how hoki forms DMA rapidly is unknown, the difference in the state of ferrous iron, which catalyzes DMA formation, may have had an effect (Mizuguchi et al., 2011a; Kobayashi et al., 2005). It is known that oxygen causes emissions of rancidity and decreases the fish quality. Minced pollock, SBW and hoki meat, mixed for $10 \mathrm{~min}$, were assessed for off-flavor after frozen storage at $-23^{\circ} \mathrm{C}$ for 6 months. The results showed there was no particular concern about rancidity or fishy smell. However, this point is of concern when fish with a high fat content is used. It was also observed that the meat temperature reached $14^{\circ} \mathrm{C}$ when the minced SBW meat was mixed for more than 20 min at room temperature and the salt solubility of the meat decreased (data not shown). Based on these results, we considered that a mixing treatment of 10 min was the optimum condition in this test.

As for the mechanism of suppression of DMA formation by the mixing treatment, Boer and Fennema reported that $\mathrm{O}_{2}$ causes the mixing treatment to inhibit DMA formation prior to freezing (Boer and Fennema, 1989) and similar results were obtained in our study using the minced SBW meat. Boer and Fennema suggested that $\mathrm{O}_{2}$ inhibits the enzymatic formation of DMA (Boer and Fennema, 1989). Reece also postulated the existence of an enzymatic DMA formation system in cod muscle and suggested that $\mathrm{O}_{2}$ also suppresses the enzymatic DMA formation system (Reece, 1983). However, TMAO is known to decompose non-enzymatically to DMA and formaldehyde during freezing by an $\mathrm{Fe}^{2+}$-catalyzed reaction (Spinelli and Koury, 1979) known as the Polonovski reaction (Monkovic et al., 1985). Thus, the mixing treatment may suppress DMA formation by increasing the exposure to $\mathrm{O}_{2}$ in the air, thereby oxidizing $\mathrm{Fe}^{2+}$ to $\mathrm{Fe}^{3+}$, which lacks any DMA formation catalytic activity (Ferris et al., 1967). $\mathrm{O}_{2}$ may also oxidize reductants such as ascorbic acid and glutathione in fish muscle. $\mathrm{Fe}^{2+}$ and reductants are normally compartmentalized in fish muscle, but they may lose their compartmentalization due to the mechanical force of mixing (MacDonald and Wilson, 1990), thereby exposing them to the oxidative environment. We observed that $\mathrm{CO}_{2}$ suppressed DMA formation when the minced SBW meat was mixed for $10 \mathrm{~min}$ in only $\mathrm{CO}_{2}$. However, it is considered that the effect of DMA suppression by the mixing treatment in the air was caused by $\mathrm{O}_{2}$ because $\mathrm{CO}_{2}$ is only present at a level of 300 ppm in the air.

Sucrose was added to all the samples used in this study. Sugars are known to suppress DMA formation (MacDonald and Wilson, 1990; Mizuguchi et al., 2011b) and inhibit protein denaturation (Sotelo and Mackie, 1993). Thus, sugars 
are essential for preserving the native functions of fish proteins during freezing.

This study showed that minced pollock and SBW meat could be maintained in a good condition during freezing after a mixing treatment. We analyzed the protein properties after the mixing treatment. It was found that the protein solubility of minced SBW meat mixed for 10 min was consistently higher than that of surimi. The difference in the protein solubility at low $\mathrm{KCl}$ concentrations will be reflected by differences in the water-soluble protein content. Minced meat from gadoid species generally produces much more DMA than surimi, but the protein solubility of the minced meat was higher than that of surimi under the high $\mathrm{KCl}$ concentrations tested in this study. This shows that mixing of the minced meat with sucrose under the conditions used in this experiment suppressed protein denaturation by inhibiting formaldehyde generation, which induced the denaturation of salt-soluble protein. Protein solubility is vital for food processing because protein dissolution is required for some desirable protein functions, such as gel formation, binding, and emulsification; thus, high solubility protein would be an advantage during food processing. The WHC of minced SBW meat was lower than that of surimi, whereas the $\mathrm{OHC}$ of the minced meat was higher than that of surimi. Watersoluble protein stabilizes the emulsified condition of fish meat (Okazaki et al., 2002); therefore, the high OHC of the minced meat was because of the high water-soluble protein content of the minced meat.

The present study showed that mixing minced fish meats with sucrose prior to freezing improved the protein stability of frozen fish meat. Our data also indicated that minced meats from gadoid species could be used as an alternative to surimi and as raw materials in various fish products if minced meats are mixed under suitable conditions. However, minced hoki meat was not stabilized by the mixing treatment because the DMA formation was significantly rapid. In future, further detailed studies are required for determining methods for improving the stability of frozen hoki. For example, if minced hoki meat is mixed only in the presence of $\mathrm{O}_{2}$, DMA formation may be suppressed to a sufficiently low level. Improving the stability of frozen minced fish meats may contribute to the more effective use of fish resources, because the preparation of minced meats does not require the leaching process used in surimi processing and the yield of minced meats is higher than that of surimi.

\section{References}

Boer, G. and Fennema, O. (1989). Effect of mixing and moisture modification on toughening and dimethylamine formation in Alaska pollock mince during frozen storage at $-10^{\circ} \mathrm{C}$. J. Food.
Sci., 54, 1524-1529.

Careche, M. and Li-chan, E.C.Y. (1997). Structural changes in cod myosin after modification with formaldehyde or frozen storage. $J$. Food Sci., 62, 717-723.

Castell, C.H., Neal, W.E. and Dale, J. (1973). Comparison of changes in trimethylamine, dimethylamine, and extractable protein in iced and frozen gadoid fillets. J. Fish Res. Board Can., 30, 12461248.

Dyer, W.J. and Mounsey, Y.A. (1945). Amines in fish muscle. II. Development of trimethylamine and other amines. J. Fish Res. Board Can., 6, 359-367.

Ferris, J.P., Gerwe, R.D. and Gapski, G.R. (1967). Detoxication mechanisms. II. The iron-catalyzed dealkylation of trimethylamine oxide. J. Am. Chem. Soc., 89, 5270-5275.

Gornall, A.G., Bardawill, C.J. and David, M.M. (1949). Determination of serum proteins by means of the biuret reaction. J. Biol. Chem., 177, 751-766.

Kawasaki, K., Ooizumi, T. and Konno, K. (1991). Effect of peroxidized fish lipid on the ATPase activity of carp myofibrils. Nippon Suisan Gakkaishi, 57, 1185-1191 (in Japanese).

Kawasaki, K., Ooizumi, T. and Konno, K. (1992). Cross-linking reaction of myosin heavy chain in carp myofibrils induced by peroxidized sardine oil. Nippon Suisan Gakkaishi, 58, 127-133 (in Japanese).

Kimura, M., Takeuchi, N., Nozawa, H., Mizuguchi, T., Kimura, I. and Seki, N. (2006). The mechanism and oxygen gas inhibition of the degradation of trimethylamine- $N$-oxide in walleye pollock muscle during storage. Nippon Suisan Gakkaishi, 72, 911-917 (in Japanese).

Kleeberg, U. and Klinger, W. (1982). Sensitive formaldehyde determination with NASH's reagent and a 'tryptophan reaction'. $J$. Pharmacol. Methods, 8, 19-31.

Kobayashi G., Matsuoka A., Mizuguchi T. and Ochiai T (2005). Isolation and characterization of fish myoglobin from hoki (Macruronus Magellanicus). Zool. Sci., 22(12), 1495.

MacDonald, G.A., Willson, N.D. and Lanier, T.C. (1990). Stabilised mince: an alternative to the traditional surimi process. In: Chilling and Freezing of New Fish Products. International Institute of Refrigeration, Paris, pp 69-76.

Mizuguchi, T., Kumazawa, K., Yamashita, S. and Safey, J. (2011a). Factors that accelerate dimethylamine formation in dark muscle of three gadoid species during frozen storage. Fish Sci., 77, 143149.

Mizuguchi, T., Kumazawa, K., Yamashita, S. and Stuart, G. (2011b). Effect of surimi processing on dimethylamine formation in fish meat during frozen storage. Fish Sci., 77, 271-277.

Monkovic, I., Wong, H. and Bachand, C. (1985). Secondary amines from the iron (II) ion-catalyzed reaction of amine oxides: a general method for the dealkylation of tertiary amines. Synthesis, $\mathbf{8}$, $770-773$. 
Okazaki, E., Yaku, S., Fukuda, Y., Sakai, T. and Nambu, S. (2002). Preventive effect of polyols on the demulsification of emulsified surimi during frozen storage. Nippon Suisan Gakkaishi, 68, 701705 (in Japanese).

Racicot, L.D., Lundstrom, R.C., Wilhelm, K.A., Ravesi, E.M. and Licciardello, J.J. (1984). Effect of oxidizing and reducing agents on trimethylamine- $N$-oxide demethylase activity in red hake muscle. J. Agric. Food Chem., 32, 459-464.

Reece, P. (1983). The role of oxygen in the production of formaldehyde in frozen minced cod muscle. J. Sci. Food Agric., 34, 11081112.

Rehbein, H. and Orlick, B. (1990). Comparison of the contribution of formaldehyde and lipid oxidation products to protein denaturation and texture deterioration during frozen storage of minced ice-fish fillet (Champsocephalus gunnari and Pseudochaenichthys georgianus). Int. J. Refrig., 13, 336-341.

Reppond, K.D., Collins, J. and Markey, D. (1985). Walleye pollock (Theragra chalcogramma): changes in quality when held in ice, slush-ice, refrigerated seawater, and $\mathrm{CO}_{2}$-modified refrigerated seawater then stored as blocks of fillets at $-18^{\circ} \mathrm{C}$. J. Food Sci., 50, 985-996.

Sato, W., Shikota, R. and Nozawa, H. (2011). Effect of storage under gaseous oxygen on degradation of trimethylamine- $N$-oxide in the muscle of Pacific saury. Nippon Suisan Gakkaishi, 77, 665673 (in Japanese).

Sotelo, C. and Mackie, I.M. (1993). The effect of formaldehyde on the aggregation behaviour of bovine serum albumin during storage in the frozen and unfrozen states in the presence and absence of cryoprotectants and other low molecular weight hydrophilic compounds. Food Chem., 47, 263-270.

Sotelo, C.G., Pineiro, C. and Perez-Martin, R.I. (1995). Denaturation of fish proteins during frozen storage: role of formaldehyde. Z. Lebensm Unters Forsch, 200, 14-23.

Spinelli, J. and Koury, B. (1979). Nonenzymic formation of dimethylamine in dried fishery products. J. Agric. Food Chem., 27, 1104-1108.

Tokunaga, T. (1964). Studies on the development of dimethylamine and formaldehyde in Alaska pollack muscle during frozen storage. Bull. Hokkaido Reg. Fish Res. Lab., 29, 108-122 (in Japanese).

Tokunaga, T. (1970). Trimethylamine oxide and its decomposition in the bloody muscle of fish. I. TMAO, TMA, and DMA contents in ordinary and bloody muscles. Nippon Suisan Gakkaishi, 36, 502-509 (in Japanese).

Tokunaga, T. (1974). The effect of decomposed products of trimethylamine oxide on quality of frozen Alaska pollock fillet. Nippon Suisan Gakkaishi, 40, 167-174 (in Japanese).

William, H. ed (2005). AOAC, Official Methods of Analysis of the Association of Official Analytical Chemists, $18^{\text {th }}$ edn. Chapt. 4.6.01, p.45, Method 962.09. Association of Official Analytical Chemists, Gaithersburg, MD. 